Nachruf

\title{
Hans Jenzer (1907-1975)
}

Von Urs Boschung

Am 18. November 1975 starb in Bern Dr. med. Hans Jenzer, Privatdozent für Geschichte der Medizin.

Hans Jenzer wurde am 6.Dezember 1907 als Sohn des Apothekers Dr.phil. Rudolf Jenzer (1877-1952) und der Bertha Moser in Interlaken geboren. Er besuchte das Gymnasium in Burgdorf und studierte in Genf und Bern Medizin. Auslandsemester verbrachte er in Berlin und Kiel. Nach bestandenem Staatsexamen (1932) führte ihn eine Studienreise nach Berlin und Paris. Als Assistent von Professor Albert Schüpbach erwarb er sich im Inselspital seine internistische Ausbildung, die ihn befähigte, 1938 in Bern eine eigene Praxis zu eröffnen; er führte sie bis zuletzt im ersten Stock seines Hauses am Falkenhöheweg. Seine Patienten schätzten ihn als «Hausarzt alter Art, gewissenhaft, stets bereit zu kommen, heiter und gütig, über ein großes Wissen verfügend» (Nachruf Nr.1).

Mannigfach sind die Dienste, die Hans Jenzer der Öffentlichkeit leistete. Als Vertrauensarzt der Bundesverwaltung und der SBB betreute er das in Bern wohnhafte Personal. Während des Zweiten Weltkrieges war er als Kompaniekommandant und Regimentsarzt eingeteilt; später leitete er als Oberstleutnant eine sanitarische Untersuchungskommission (UC). Seit 1963 amtete er als Ortspräsident der Eidgenössischen Medizinalprüfungen in Bern. Jeder Kandidat hatte sich bei ihm persönlich anzumelden. Er organisierte den Ablauf der Examina keine leichte Aufgabe bei den großen Studentenzahlen. Am Schluß gab er dem Prüfling Erfolg oder Mißerfolg bekannt und unterschrieb das Zeugnis. 1969 übernahm Jenzer zusätzlich den Vorsitz des (gesamtschweizerischen) Leitenden Ausschusses für die Eidgenössischen Medizinalprüfungen. In seine Amtszeit fiel die sogenannte «Experimentierphase» der Studienreform. «Sein Hauptanliegen neben der Entlastung des Studenten war die Erhaltung eines einheitlichen schweizerischen Studienganges. Dennoch setzte er sich unermüdlich für die Verwirklichung der in den einzelnen Fakultäten entwickelten neuen Lösungen ein » (Nachruf Nr.2).

Dem Vielbeschäftigten blieb wenig Freizeit. Konzerte und Bergwanderungen brachten Abwechslung. Alljährlich besuchte er mit seiner Gattin und einigen Dienstkameraden historische Stätten. Im engsten Kreis las er mit befreundeten Philosophen und Philologen Texte von Plato. Platos Äußerungen über Stellung 
und Aufgabe des Arztes sprachen ihn an und führten ihn zur Medizingeschichte. Seit 1960 nahm er an den Sigerist-Konferenzen teil, ebenso an den Jahresversammlungen der SGGMN. Ausgedehnte Studien widmete er Johann Friedrich von Herrenschwand (1715-1798), dem aus Murten stammenden, später in Bern eingebürgerten Leibarzt des polnischen Königs. Auf einer Reise nach Warschau und Krakau fand er Zugang zu unbekannten Quellen. 1967 veröffentlichte er die Ergebnisse in seiner Habilitationsschrift. Von 1965 bis 1966 hielt er an der Universität Bern die Vorlesung «Einführung in die Innere Medizin»; nach seiner Habilitation am 15. August 1966 erhielt er auch den Lehrauftrag für Geschichte der Medizin. Anfangs 1971 zwang ihn jedoch ein Herzinfarkt, seine Tätigkeit einzuschränken. Vor die Entscheidung gestellt, zog er das Mitgestalten der Gegenwart und Zukunft historischer Reflexion vor. So mußte auch die ausführliche Darstellung der ärztlichen Tätigkeit I.P. V.Troxlers unterbleiben.

Hans Jenzer sah Herrenschwands Lebenswerk in seinen «Bestrebungen, die Ausbildung der jungen Ärztegeneration zu verbessern ». Hier hat er durch Übernahme großer, zeitraubender und wenig dankbarer Aufgaben selbst sein Bestes gegeben. Dafür gebührt ihm allgemeine Anerkennung.

Veröffentlichungen

- 17. Internationaler Kongreß für Geschichte der Medizin in Athen und Kos vom 4. bis 14.September 1960, Internationale Hippokrates-Stiftung von Kos. Gesnerus 17 (1960) 168.

- Der Arzt in den späten Schriften Platos. Verhandl. d. Schweiz. Naturforsch. Ges. $1960,145 \mathrm{f}$.

- Johann Friedrich von Herrenschwand, ein bedeutender Berner Arzt im 18. Jahrhundert. Verhandl. d. Schweiz. Naturforsch. Ges. 1963, 139 f.

- Das ärztliche Ethos im siebenten Brief Platos. Sudhoffs Archiv für Gesch.d. Med. u. d. Naturwissensch. 48 (1964) 1-17.

- Das medizinische Werk von Ignaz Paul Vital Troxler. Verhandl. d. Schweiz. Naturforsch. Ges. 1966, $174 \mathrm{f}$.

- Die Gründung der Hebammenschulen in der Schweiz im 18. Jahrhundert (mit besonderer Berücksichtigung der bernischen Verhältnisse). Gesnerus 23 (1966) 67-77.

- Dr. med. Johann Friedrich von Herrenschwand. Ein Berner Arzt im 18. Jahrhundert. Bern, Francke Verlag, 1967; 266 S., ill. [Habilitationsschrift]. 
- Die Spezialisierung in der Medizin historisch gesehen. Schweiz. Arztezeitung 48 (1967) 825-831 [Antrittsvorlesung].

- Über die wenig bekannte Geschichte der schweizerischen Medizin von I.P.V. Troxler. Verhandl. d. Schweiz. Naturforsch. Ges. 1969, $174 \mathrm{f}$.

Geleitete Dissertationen (Diss. med. Bern)

- Matter, Lukas Christoph A.: Hans Carossa als Arzt. 1972.

- Bürgi, Hans-Jörg: Das Spitalwesen im Kanton Solothurn unter besonderer Berücksichtigung der nichtstaatlichen Spitäler Dornach, Breitenbach und Grenchen. 1973.

- Ninck, Martin: Die Gründungsgeschichte der berneroberländischen Bezirksspitäler. 1973.

- Schopfer, Kurt: Giftverabreichung, Abtreibung, Blasensteinschnitt. Die Forderungen im hippokratischen Eid und die Aufzeichnungen im Corpus Hippokraticum in einer Gegenüberstellung. 1973.

- Streuli, Rolf: Johann Jakob Guggenbühl und die Kretinenheilanstalt auf dem Abendberg bei Interlaken. 1973.

Hans Jenzer war von 1968 bis 1971 Mitherausgeber der «Berner Beiträge zur Geschichte der Medizin und der Naturwissenschaften».

Nachrufe für Hans Jenzer

- Oberländisches Volksblatt - Echo von Grindelwald, 14.1.1976, S.4 (zit. «Nachruf Nr.1»).

- Schweizerische Ärztezeitung 56 (1975) 1709 (zit. «Nachruf Nr. $2 »)$. 